\title{
Evaluation of microstructural, magnetic surface/near-surface chemical state analysis nanoparticle
}

\author{
E. Ranjith Kumar ${ }^{1, *}$, A. Balamurugan ${ }^{2}$ \\ ${ }^{1}$ Department of Physics, KPR Institute of Engineering and Technology, Coimbatore-641407, Tamil Nadu, India \\ 2 Department of Physics, Government Arts and Science College, Avinashi - 641654, Tamil Nadu, India \\ *Corresponding author Email: ranjueaswar@gmail.com \\ DOI: https://doi.org/10.34256/irjmt2123 \\ Received: 10-02-2021, Revised: 07-03-2021, Accepted: 08-03-2021, Published: 10-03-2021
}

Abstract: Nanocrystalline $\mathrm{Mn}$ substituted $\mathrm{CuFe}_{2} \mathrm{O}_{4}$ nanoparticles (MCFNPs) were synthesized using urea and egg white. The effects of heat treatment on crystal structure and magnetic properties have been studied using X-ray diffractometer (XRD) and Vibrating Sample Magnetometer (VSM). The single-phase cubic spinel structure of as synthesized MCFNPs was recognized from XRD profile. There are some impurity peaks in the annealed samples, which are the decomposition of the ferrites at higher annealing temperatures to the $\alpha-\mathrm{Fe}_{2} \mathrm{O}_{3}$ phase. The crystallite size and Lattice parameter of the samples increases with annealing temperature. The crystallite sizes of the MCFNPs were found in the range $\sim 10$ to $55 \mathrm{~nm}$. The morphology and particle size of the sample (annealed at 900 ${ }^{\circ} \mathrm{C}$ ) have been recorded through SEM and TEM. The secondary non-magnetic impurity phase influences the magnetic nature of the samples. The saturation magnetization (Ms) decreases at a temperature of $600{ }^{\circ} \mathrm{C}$ due to the presence of non-magnetic $\alpha-\mathrm{Fe}_{2} \mathrm{O}_{3}$ phase. The surface / near-surface chemical states of the $900{ }^{\circ} \mathrm{C}$ annealed MCFNPs were analyzed using XPS within a range of $0-1000 \mathrm{eV}$ binding energies.

Keywords: Nanomaterials, Chemical synthesis, Structural analysis, Magnetic properties, X-ray photoelectron spectroscopy.

\section{Introduction}

Spinel ferrite is of particular interest due to its potential use in a variety of fields, from scientific and electronic applications to sindustrial applications [1]. Fine magnetic particles are now the subject of study due to their many technical applications. One of the most interesting uses of magnetic materials is treatment with hyperthermia, which is known to be an alternative treatment for chemotherapy, radiotherapy and surgery in cancer therapy [2]. The structure, size and morphology are related to the conditions of preparation and strongly determine the properties of $\mathrm{MnFe}_{2} \mathrm{O}_{4}$. The preparation of $\mathrm{NiFe}_{2} \mathrm{O}_{4}, \mathrm{MnFe}_{2} \mathrm{O}_{4}, \mathrm{Ni}$ and $\mathrm{Zn}$ ferrites has been reported by several groups [35]. Because of its excellent magnetic properties, along with electrical and semiconducting properties, many researchers are interested in studying the various physical properties of $\mathrm{CuFe}_{2} \mathrm{O}_{4}$ [6]. The magnetic activity of $\mathrm{CuFe}_{2} \mathrm{O}_{4}$ has attracted a great deal of interest and has been the subject of extensive studies. Recently, using a sonication method, M.A.S. Amulys et al., [7] synthesized nanostructured spinel $\mathrm{MnFe}_{2} \mathrm{O}_{4}$ with different grain sizes ranging from 16 to $24 \mathrm{~nm}$ and studied their photocatalytic activities. H. B. Desai et al., [8] reported $\mathrm{MnFe}_{2} \mathrm{O}_{4}$ with an auto combustion process of $40 \mathrm{~nm}$ grain size for photocatalytic applications. S. V. Bhandare, et al., [9] prepared $\mathrm{MnFe}_{2} \mathrm{O}_{4}$ nanoparticles by sol gel combustion synthesis and analyzed their magnetic properties for different annealing temperature. For the synthesis of magnetic nanoparticles, many methods have been developed, including thermal decomposition, co-precipitation, polyol, reverse microemulsion, microwave combustion, and combustion methods [10]. The combustion method is a very successful and promising technique among the preparation methods, because the particles produced by this method are pure and uniform with a limited distribution of sizes. In this research, a simple urea and egg white assisted combustion method was favored over the synthesis of $\mathrm{Mn}$ substituted $\mathrm{CuFe}_{2} \mathrm{O}_{4}$ nanoparticles. The goal was to research the effects of heat treatment on the size of the particles and magnetic properties of the $\mathrm{CuFe}_{2} \mathrm{O}_{4}$ nanoparticles substituted by $\mathrm{Mn}$. The thorough investigation of the properties 
impacted by the size is analyzed and the findings are summarized.

\section{Experimental methods}

\subsection{Synthesis}

$\mathrm{Mn}$ substituted $\mathrm{CuFe}_{2} \mathrm{O}_{4}$ nanoparticles have been prepared by urea and egg white assisted combustion method. In this present work, Urea and egg white were used as a fuel to prepare nanoparticles in combustion process. Analytical grade (Merck) $\mathrm{Mn}$ $\left(\mathrm{NO}_{3}\right)_{2} 6 \mathrm{H}_{2} \mathrm{O}, \mathrm{Cu}\left(\mathrm{NO}_{3}\right)_{2} 6 \mathrm{H}_{2} \mathrm{O}, \mathrm{Fe}\left(\mathrm{NO}_{3}\right)_{3} 9 \mathrm{H}_{2} \mathrm{O}$ were used as raw materials to prepare $\mathrm{Mn}-\mathrm{CuFe}_{2} \mathrm{O}_{4}$ nanoparticles. These materials are taken at appreciable molar concentrations to maintain stoichiometric as 1:2. The solutions of precursors are mixed with $50 \mathrm{ml}$ of egg white solution which is acting as a chelating agent. This solution mixture was thoroughly stirred for $1 \mathrm{~h}$. The mixed solution was further stirred under heating at $100^{\circ} \mathrm{C}$ using magnetic stirrer until to get desired final ferrite powder. The procedure has been repeated with $50 \%$ of urea instead of egg white solution. The ferrite powder obtained was milled into a fine powder in an agate mortar and a part of the powder was heat treated in the air at $600^{\circ} \mathrm{C}$ and at $900^{\circ} \mathrm{C}$.

\subsection{Characterization techniques}

The list of characterizations and instruments details are given in table 1.

\section{Results and discussion}

Structure evaluation of the nanocrystallized products of MCFNPs synthesized using urea and egg white annealed at $600^{\circ} \mathrm{C}$ and $900^{\circ} \mathrm{C}$ was performed by $\mathrm{XRD}$ and the diffraction spectra is presented in Fig. 1a \& Fig.2a. All the diffraction peaks observed were indexed by the JCPDS card indicating that the products of the MCFNPs are the cubic spinel structure. The appearance of secondary impurity peaks from the spectrum XRD indicates that the $\alpha-\mathrm{Fe}_{2} \mathrm{O}_{3}$ phase was decomposed at $600{ }^{\circ} \mathrm{C}$ [11-13]. The intensity of the secondary peaks slowly vanished at a higher temperature of $900{ }^{\circ} \mathrm{C}$. The diffraction peaks become narrower and sharper, indicating an improvement in particle size and crystallinity after annealing. The average crystallite size of the products was determined using the formula Debye-Scherer $(t=0.9 \lambda / \beta \cos \theta)$. The lattice constant (a) was determined from the XRD profile using the formula $a 2=d 2 /\left(h^{2}+k^{2}+l^{2}\right)$. The crystalline size ( $t$ ) and the lattice constant (a) of the products are shown in Table 2. The crystalline sizes of the MCFNPs samples are located in the range 9.4 to $46.6 \mathrm{~nm}$ for urea-assisted synthesis and 14.9 to 54.8 $\mathrm{nm}$ for egg white induced synthesis. Typical external morphologies of the $900{ }^{\circ} \mathrm{C}$ annealed MCFNP samples recorded by SEM are shown in Fig. $1 \mathrm{~b}$ and $2 \mathrm{~b}$. The morphology of the samples (Fig. $1 b$ and $2 b$ ) of MCFNPs has irregular and spherical shaped particles with a slight agglomeration, which may have the effect of replacement of $\mathrm{Mn}$, defects and also the effect of annealing [12]. As shown in Fig.1c and Fig2c, the transmission electron microscope (TEM) examined the microstructure and particle size of the $900^{\circ} \mathrm{C}$ annealed MCFNPs samples. The microstructure, size and shape of the products identified by the SEM morphologies can be clearly confirmed.

Due to comparatively higher temperatures and interactions between magnetic nanoparticles, agglomeration can be understood at higher temperatures. There is also an inevitable grade of agglomeration at higher temperatures [12]. The particle sizes of the MCFNPs are compatible with the XRD research findings. At the top right of the Figs. 1c \& 2c, the corresponding selected area electron diffraction (SAED) pattern of MCFNPs are shown. The superimpositions of the bright spots demonstrate with equal lattice arrangement the strong crystalline existence of the samples.

Table 1 Characterization/instrument details

\begin{tabular}{|l|l|l|}
\hline Crystal properties & Techniques & Instrument model \\
\hline Structural analysis & X-Ray Diffraction & Phillip's X'pert-PRO with a target CuKa ${ }_{1}(\lambda=1.5406 \AA)$ \\
\hline Morphology & Scanning Electron Microscopy & JEOL JSM-6610L at 20 kV \\
\hline Microstructure & Transmission Electron Microscopy & Technai G20-stwin at 200 kV \\
\hline Magnetic properties & Vibrating Sample Magnetometer & Lakeshore VSM 7410 \\
\hline Chemical states & X-ray Photoelectron Spectroscopy & PHI 5000 VersaProbe III \\
\hline
\end{tabular}



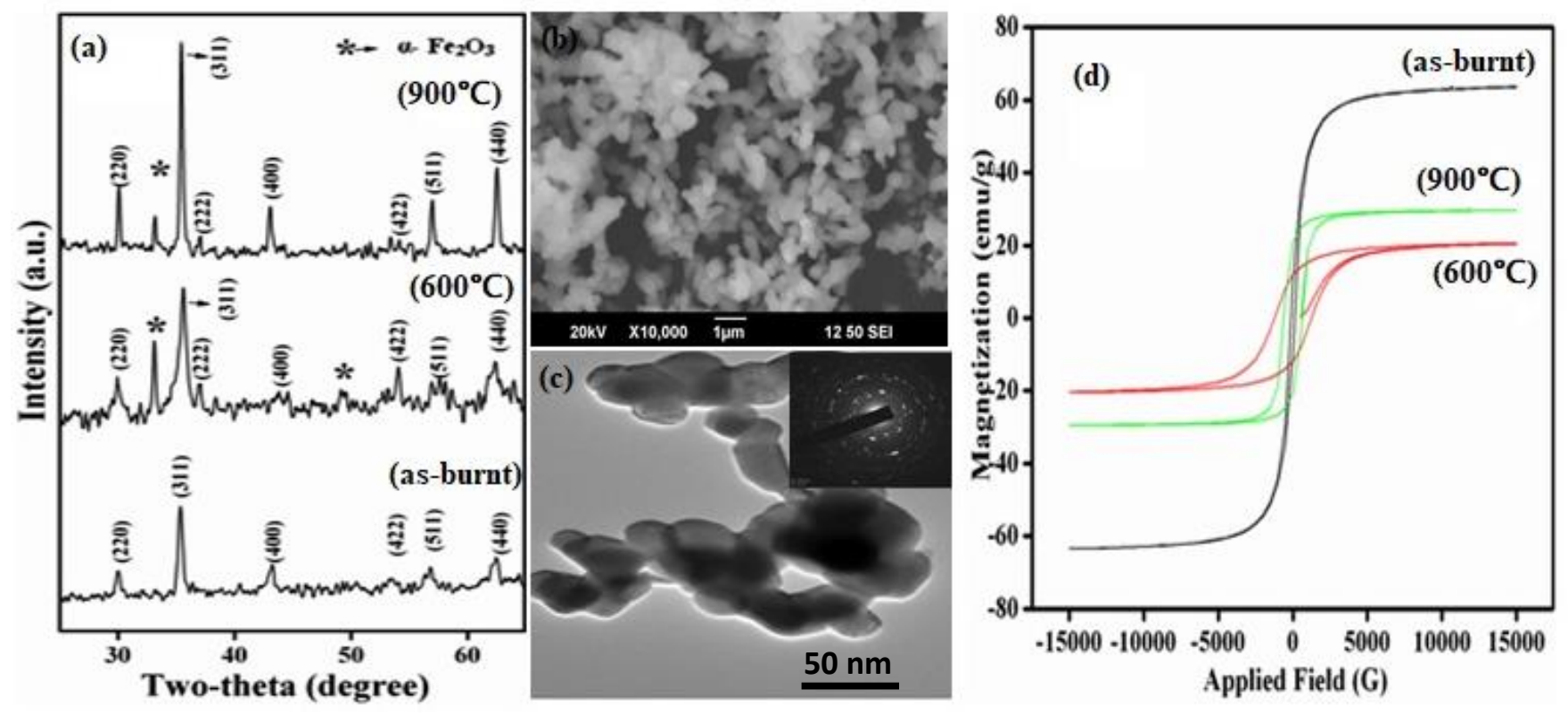

Figure 1 Shows structural and magnetic analysis of MCFNPs prepared using urea
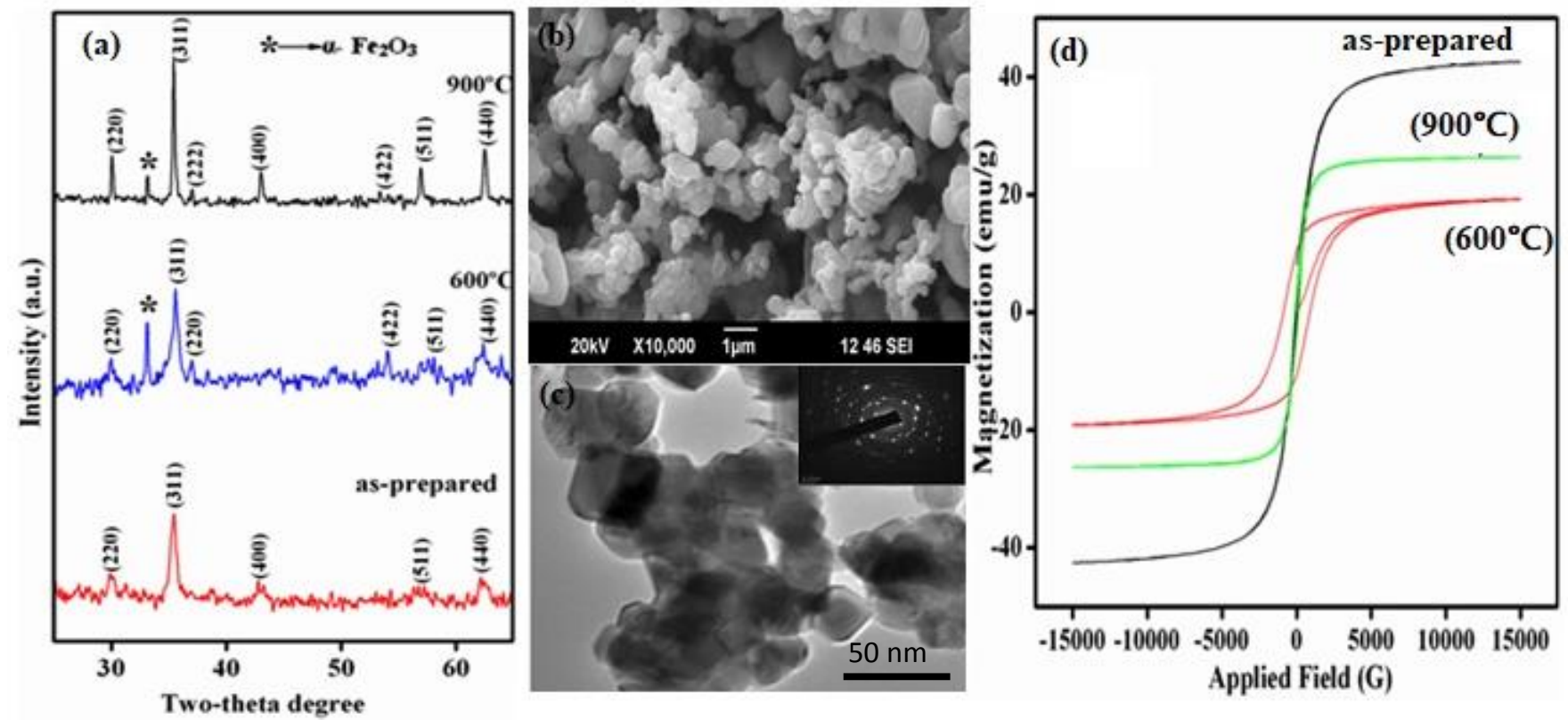

Figure 2 shows structural and magnetic analysis of MCFNPs using egg white.

Table 2 Structural and magnetic parameters of MCFNPs using urea and egg white

\begin{tabular}{|l|l|l|l|l|l|l|}
\hline \multirow{2}{*}{ Crystal parameters } & \multicolumn{3}{|l|}{ MCFNPs using Urea } & \multicolumn{2}{l|}{ MCFNPs using Egg white } \\
\cline { 2 - 8 } & as-burnt & $\mathbf{6 0 0}{ }^{\circ} \mathrm{C}$ & $\mathbf{9 0 0}{ }^{\circ} \mathrm{C}$ & as-prepared & $\mathbf{6 0 0}{ }^{\circ} \mathrm{C}$ & $\mathbf{9 0 0}{ }^{\circ} \mathrm{C}$ \\
\hline Crystallite size (t) nm & 9.4 & 16.3 & 46.6 & 14.9 & 27.1 & 54.8 \\
\hline Lattice constant (a) $\AA$ & 8.41 & 8.42 & 8.43 & 8.38 & 8.39 & 8.41 \\
\hline Saturation magnetization (Ms) emu/g & 63.87 & 19.85 & 29.12 & 42.6 & 20.7 & 27.8 \\
\hline $\begin{array}{l}\text { Coercivity (Hc) G } \\
\text { F }\end{array}$ & 120.2 & 236.9 & 151.4 & 110.5 & 308.5 & 98.2 \\
\hline
\end{tabular}



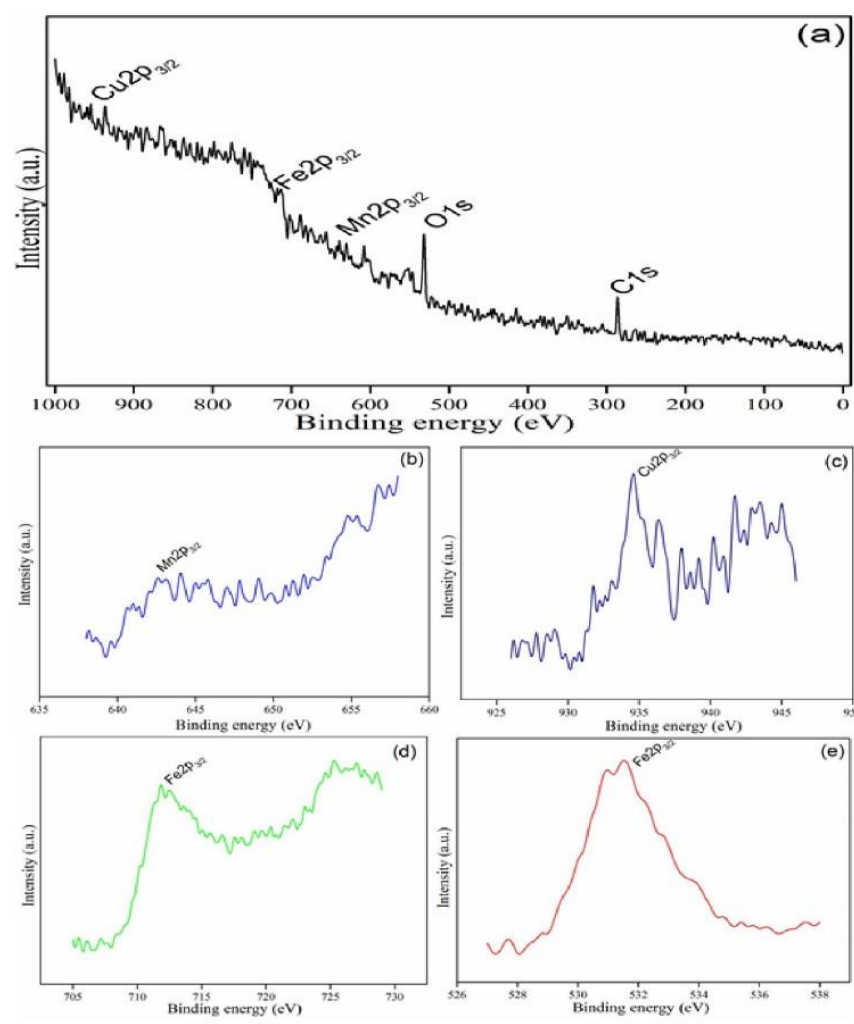

Figure 3 XPS spectrum of MCFNPs prepared using urea assisted synthesis method
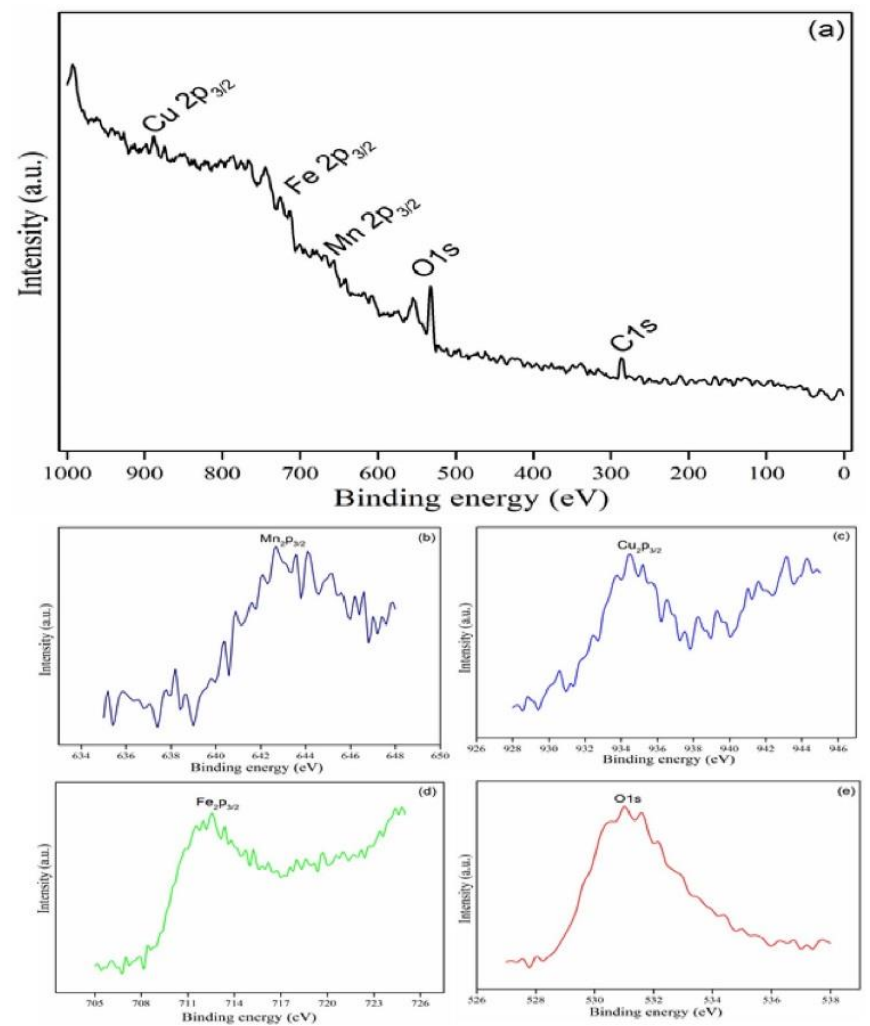

Figure 4 XPS spectrum of MCFNPs prepared using egg white mediated synthesis method

Fig. 1d \& Fig.2d displays room temperature magnetic measurements by vibrating sample magnetometer (VSM) of MCFNPs prepared using urea and egg white induced combustion synthesis. Basic magnetic parameters such as saturation magnetization (Ms) and coercivity ( $\mathrm{Hc})$ of as-synthesized and annealed at different temperatures $\left(600^{\circ} \mathrm{C}\right.$ and $900^{\circ}$ C) of MCFNP are shown in Table 2. The size of the particle and the purity of the phase have a significant role to play in the magnetic parameters. From the findings of $X R D$, the size of the particles increases with an increase in annealing procedure. Generally, the saturation magnetization of spinel ferrite nanoparticles increases with a rise in size due to the effect of heat treatment. Due to the presence of secondary phase (non-magnetic) at higher annealing temperature, magnetization decreases at $600{ }^{\circ} \mathrm{C}$. At $900{ }^{\circ} \mathrm{C}$, the saturation magnetization of the annealed MCFNPs is higher than that of $600{ }^{\circ} \mathrm{C}$, which may be the particle size, and the secondary peaks of the products may vanish [12]. The higher coercive values of the $600^{\circ} \mathrm{C}$ annealed MCFNPs using urea and egg white are 236.9 $G$ and $308.5 \mathrm{G}$, which may be attributed to the difference in the anisotropic field of the ions present in the sample by thermal annealing.

Fig. 1d \& Fig.2d displays room temperature magnetic measurements by vibrating sample magnetometer (VSM) of MCFNPs prepared using urea and egg white induced combustion synthesis. Basic magnetic parameters such as saturation magnetization (Ms) and coercivity ( $\mathrm{Hc})$ of as-synthesized and annealed at different temperatures $\left(600^{\circ} \mathrm{C}\right.$ and $900^{\circ}$ C) of MCFNP are shown in Table 2. The size of the particle and the purity of the phase have a significant role to play in the magnetic parameters. From the findings of XRD, the size of the particles increases with an increase in annealing procedure. Generally, the saturation magnetization of spinel ferrite nanoparticles increases with a rise in size due to the effect of heat treatment. Due to the presence of secondary phase (non-magnetic) at higher annealing temperature, magnetization decreases at $600{ }^{\circ} \mathrm{C}$. At $900{ }^{\circ} \mathrm{C}$, the saturation magnetization of the annealed MCFNPs is higher than that of $600{ }^{\circ} \mathrm{C}$, which may be the particle size, and the secondary peaks of the products may vanish $[12,14,15]$. The higher coercive values of the $600^{\circ} \mathrm{C}$ annealed MCFNPs using urea and egg white are $236.9 \mathrm{G}$ and $308.5 \mathrm{G}$, which may be attributed to the difference in the anisotropic field of the ions present in the sample by thermal annealing.

\section{Conclusion}

The structural, magnetic and surface chemical state analysis of MCFNPs prepared by using urea and egg white were investigated. The heat treatment effects on particle size and phase purity of the MCFNPs were 
documented. The existence of secondary impurity phase, due to the decomposition of MCFNPs at higher annealing temperature recorded using XRD profiles. Spherical shaped agglomerated magnetic nanoparticles in the range of 40 to $50 \mathrm{~nm}$ examined through TEM. The decrement of secondary (nonmagnetic) phase at higher annealing $\left(900^{\circ} \mathrm{C}\right)$ temperature leads to the better magnetization than the sample annealed $600{ }^{\circ} \mathrm{C}$ is evident that the magnetic parameters influenced more by the phase purity of the products. The binding energies of presented elements were labeled from XPS spectra, which clearly show the surface chemical states of MCFNPs.

\section{References}

[1] N. A. Masmali, Z. Osman, A. K. Arof, Recent developments in zinc-based two-cation oxide spinels: From synthesis to applications, Ceramics International, 47(3) (2020) 2949-2962. https://doi.org/10.1016/j.ceramint.2020.09.249

[2] K. K. Kefeni, T. A. M. Msagati, T. TI. Nkambule, B. B. Mamba, Spinel ferrite nanoparticles and nanocomposites for biomedical applications and their toxicity, Materials Science and Engineering: C, 107 (2020)

110314.

https://doi.org/10.1016/j.msec.2019.110314

[3] P. Aji Udhaya, M. Meena, Albumen Assisted Green Synthesis of $\mathrm{NiFe}_{2} \mathrm{O}_{4}$ Nanoparticles and Their Physico-Chemical Properties, Materials Today: Proceedings, 9(3) (2019) 528-534. https://doi.org/10.1016/j.matpr.2018.10.372

[4] K. Sarkar, R. Mondal, S. Dey, S. Kumar, Cation vacancy and magnetic properties of $\mathrm{ZnFe}_{2} \mathrm{O}_{4}$ microspheres, Physica B: Condensed Matter, 583 (2020)

412015.

https://doi.org/10.1016/j.physb.2020.412015

[5] S.R. Sabale, Studies on catalytic activity of $\mathrm{MnFe}_{2} \mathrm{O}_{4}$ and $\mathrm{CoFe}_{2} \mathrm{O}_{4}$ MNPs as mediators in hemoglobin-based biosensor, Materials Today: Proceedings, $23 \quad$ (2020) 139-146. https://doi.org/10.1016/j.matpr.2020.02.011

[6] B. Saravanakumar, S. P. Ramachandran, G. Ravi, V. Ganesh, R.K. Guduru, R. Yuvakkumar, Electrochemical performances of monodispersed spherical $\mathrm{CuFe}_{2} \mathrm{O}_{4}$ nanoparticles for pseudocapacitive applications, Vacuum, 168 (2019) 108798. https://doi.org/10.1016/i.vacuum.2019.108798

[7] M. A. Shilpa Amulya, H. P. Nagaswarupa, M. R. Anil Kumar, C. R. Ravikumar, K. B. Kusuma, Sonochemical synthesis of $\mathrm{MnFe}_{2} \mathrm{O}_{4}$ nanoparticles and their electrochemical and photocatalytic properties, Journal of Physics and Chemistry of Solids, $\quad 148 \quad 109661$. https://doi.org/10.1016/j.jpcs.2020.109661

[8] H. B. Desai, L.J. Hathiya, H. H. Joshi, A. R. Tanna, Synthesis and Characterization of Photocatalytic $\mathrm{MnFe}_{2} \mathrm{O}_{4} \quad$ Nanoparticles, Materials Today: Proceedings, 21(4) (2020) 1905-1910. https://doi.org/10.1016/i.matpr.2020.01.248

[9] S.V. Bhandare, R. Kumar, A.V. Anupam, H.K. Choudhary, V.M. Jali, B. Sahoo, Annealing temperature dependent structural and magnetic properties of $\mathrm{MnFe}_{2} \mathrm{O}_{4}$ nanoparticles grown by solgel auto-combustion method, Journal of Magnetism and Magnetic Materials, 433 (2017) 29-34. https://doi.org/10.1016/i.jmmm.2017.02.040

[10] V. V. Deshmukh, H. P. Nagaswarupa, N. Raghavendra, Development of Co-doped $\mathrm{MnFe}_{2} \mathrm{O}_{4}$ nanoparticles for electrochemical supercapacitors, Ceramics International, https://doi.org/10.1016/j.ceramint.2020.07.191

[11]E. Ranjith Kumar, R. Jayaprakash, M. S. Seehra, T. Prakash, Sanjay Kumar, Effect of $\alpha-\mathrm{Fe}_{2} \mathrm{O}_{3}$ phase on structural, magnetic and dielectric properties of $\mathrm{Mn}-\mathrm{Zn}$ ferrite nanoparticles, Journal of Physics and Chemistry of Solids, 74 (2013) 943-949. https://doi.org/10.1016/i.jpcs.2013.02.013

[12] P. Hu, H-b. Yang, D-a. Pan, H. Wang, J-j. Tian, Sg. Zhang, X-f. Wang, Alex A. Volinsky, Heat treatment effects on microstructure and magnetic properties of $\mathrm{Mn}-\mathrm{Zn}$ ferrite powders, Journal of Magnetism and Magnetic Materials, 322(1) (2010) 173-177.

\section{https://doi.org/10.1016/j.jmmm.2009.09.002}

[13]E. Ranjith Kumar, R. Jayaprakash, J. Chandrasekaran, Effect of fuel ratio and impact of annealing temperature on particle size, magnetic and dielectric properties of manganese substituted $\mathrm{CuFe}_{2} \mathrm{O}_{4}$ nanoparticles, Supperlattices and Microstructures, $63 \quad$ (2013) 343-353. https://doi.org/10.1016/j.spmi.2013.10.001

[14]G.C. Allen, K.R. Hallam, Characterisation of the spinels $\mathrm{M}_{\mathrm{x}} \mathrm{Co}_{1-\mathrm{x}} \mathrm{Fe}_{2} \mathrm{O}_{4}(\mathrm{M}=\mathrm{Mn}$, Fe or $\mathrm{Ni})$ using $\mathrm{X}$ ray photoelectron spectroscopy, Applied Surface Science, 93(1) (1996) 25-30. https://doi.org/10.1016/0169-4332(95)00186-7

[15] T. Yamashita, P. Hayes, Analysis of XPS spectra of $\mathrm{Fe}^{2+}$ and $\mathrm{Fe}^{3+}$ ions oxide materials, Applied Surface Science, $254 \quad$ (2008) 2441-2449. https://doi.org/10.1016/j.apsusc.2007.09.063 


\section{Authors Contribution}

Conceptualization, methodology, manuscript preparation, review and editing (E. Ranjith Kumar). Manuscript Review and Editing (A. Balamurugan). All the authors have read and approved the manuscript.

\section{Conflict of interest}

The authors have no conflicts of interest to declare that they are relevant to the content of this article.

\section{Does the Article Screened for Similarity?}

Yes.

\section{Data Availability}

No additional data are available.

\section{Ethics Approval}

Ethics approval doesn't require for this study

\section{Funding}

No funding was received for conducting this study.

\section{About The License}

(C) The author(s) 2021. The text of this article is open access and licensed under a Creative Commons Attribution 4.0 International License

\section{Cite this Article}

E. Ranjith Kumar, A. Balamurugan, Evaluation of microstructural, magnetic properties and surface/nearsurface chemical state analysis of $\mathrm{Mn}-\mathrm{CuFe}_{2} \mathrm{O}_{4}$ nanoparticle, International Research Journal of Multidisciplinary Technovation, Vol 3, Iss 2 (2021) 14-.19 DOI: https://doi.org/10.34256/irjmt2123 